\section{G232 WHAT ARE PARENTS' AND STAFF MEMBERS' PERCEPTIONS AND EXPERIENCES OF THE CRANIOFACIAL MULTIDISCIPLINARY TEAM CLINIC AS A PROVIDER OF COMPREHENSIVE AND CO-ORDINATED CARE?}

AR White. Craniofacial, Great Ormond Street, London, UK

\subsection{6/archdischild-2015-308599.225}

The aim of the study was to explore the perceptions and experiences of both the multidisciplinary team and the parents who attend the monthly multidisciplinary team clinic (CRANF). This was achieved using three focus groups.

The theoretical framework for this study was based on an interpretative phenomenological approach which focuses on understanding rather than explanation (Grix 2004).

Two focus groups were with parents and one with members of the multidisciplinary team who attend CRANF. The method of analysis was through the framework approach for defining concepts and systematically analysing the data (Ritchie and Spencer 1994). Four themes for the parents' groups and four for the multidisciplinary team group were constructed from analysis of the transcripts.

Key findings from the parents' focus groups were that the experience of attending CRANF could be "daunting". Factors affecting this included numbers of professionals in the room, long waiting times and having a child present who was vulnerable due to their age or cognitive ability.

The multidisciplinary team focus group showed some congruity with the parents and an awareness of their issues. Discussion revolved more around how to "fix" the clinic rather than not have this particular type of clinic as part of the service.

It is concluded that the CRANF clinic requires some re-organisation in order to meet the needs of those who attend either as service users or service providers. Themes identified within the experience would allow for the development of this service. Further research into the experiences of all involved in multidisciplinary team clinics with a focus on the children themselves is needed.

\section{G233(P) FAMILY SUPPORT PROVISION BY THE NURSING TEAM IN NEUROREHABILITATION FOLLOWING ACQUIRED BRAIN INJURY (ABI) IN CHILDREN AND YOUNG PEOPLE}

EA Bray, LM Kliem. The Research Department, The Children's Trust, Tadworth, UK

10.1136/archdischild-2015-308599.226

Aims To examine how family support is provided by the nursing team following acquired brain injury (ABI) in a neurorehabilitation setting within the context of the multidisciplinary team.

Methods One specialist paediatric rehabilitation centre $n=23$

7 week period

Children and young people aged 2 to 18 years

Acquired brain injury

Retrospective data analysis using the Northwick Park Therapy Dependency Assessment (NPTDA) and the Northwick Park Nursing Dependency Scale (NPDS).

The NPTDA provides an assessment of a patient's therapy dependency, including family support, and is designed for use in neurorehabilitation settings where rehabilitation is provided by a multi-disciplinary team.

The NPDS provides a measure of care including patient/family psychological support provided by the nursing team. Examined family support processes and relevant training opportunities.
Results Time spent supporting families

The nursing team provide an average of $5.1 \mathrm{~h}$ (range $0.1-$ 22.5) family support per week to families of children with ABI.

The total time other team members combined (including psychologists and social workers) spent in family support was an average of $2.2 \mathrm{~h}$ per week.

Processes/systems in place

The nursing team work collaboratively with psychology and social work team to ensure a team approach in providing family support

Training provided

The psychology and nursing teams prepare a case study prior to each child's admission to ensure the nursing team have a good insight and understanding into the child's brain injury and family dynamics.

The nursing team need to have a good knowledge and understanding of $\mathrm{ABI}$ to effectively support parents and receive training to support this.

The nursing team receive training in communication, managing grief and loss and the importance of giving information whilst maintaining realistic hope.

Conclusions The nursing team have a higher number of direct contact hours with families in neurorehabilitation compared to other members of the multidisciplinary team.

Nurses need training to be able to give the level of family support and information that is required.

Nurses in the acute setting can begin to support families and prepare them for the rehabilitation journey.

\section{G234(P) HOW CHILDREN AND YOUNG PEOPLE SELF-MANAGE THEIR CHRONIC ILLNESS: GIVING CHILDREN A VOICE THROUGH PHOTO-ELICITATION}

\begin{abstract}
1,2,3 B Carter, ${ }^{4} \mathrm{~A}$ Dickinson, ${ }^{5,6} \mathrm{~K}$ Ford, ${ }^{2,5} \mathrm{~L}$ Bray, ${ }^{3.7} \mathrm{~T}$ Water, ${ }^{1,2} \mathrm{~J}$ Arnott. ${ }^{1}$ School of Health, University of Central Lancashire, UK; ${ }^{2}$ Children's Nursing Research Unit, Alder Hey Children's NHSFT, Liverpool, UK; ${ }^{3}$ School of Health Sciences, University of Tasmania, Tasmania, Australia; ${ }^{4}$ Centre for Child Health Research, Auckland University of Technology, Auckland, New Zealand; ${ }^{5}$ Faculty of Health and Social Care, Edge Hill University, Liverpool, UK; ${ }^{6}$ Practice Development Unit, Royal Hobart Hospital, Tasmania, Australia; ${ }^{7}$ Research Centre, Starship Children's Health, Auckland, New Zealand
\end{abstract}

10.1136/archdischild-2015-308599.227

Aim To explore children's understanding and perception of their chronic illness and how this shapes their lives.

Methods A qualitative, participatory methodology that acknowledged the children's agency underpinned the study. We used photo-elicitation (photographs and interviews) to build knowledge grounded in the children's experiences. Forty-five children (6-12 years) from different diagnostic groups were recruited from hospital-based and support group settings in England, Tasmania and New Zealand. The children were given digital cameras and asked to record aspects of their lives and chronic illness. Children also had the option of including pre-existing photographs into the study. The researchers then undertook audio-recorded interviews that were guided by the photographs that the children wished to talk about. Most interviews were undertaken in the child's home. We undertook interpretative thematic analysis of the interviews and content analysis of the photographs.

Results Brokering was a key concept that underpinned the children's ways of accommodating the demands of chronic illness. The children focused on 'I can.......' rather than 'I can't.......' and were able to talk with confidence about certain aspects of selfmanagement. The children used creative strategies to be like 
other children' and many were adept at negotiating risks and benefits in order to 'fit in'. Chronic illness - to a greater or lesser extent - was 'always there' but it was often successfully backgrounded through careful planning. The children actively foregrounded their achievements and focused on 'getting on' with being a child. This was not always easy. Whilst there was evidence of much resilience, this took effort and imagination from the children and their families. The children's parents/ carers provided an important role in supporting the children's ability to self-manage their illness.

Conclusion Brokering and self-management were evident in the stories children told about themselves. The use of photo-elicitation gave the children control over those facets of their lives they wanted to discuss and share with the researchers. We found it a useful tool to discover those things that were important to the children and how they were active in ensuring that they could say 'I can.....'

\section{G235 HOLDING CHILDREN FOR CLINICAL PROCEDURES; AN ETHICAL CONSIDERATION OF THE EVIDENCE}

1,2 L Bray, 2,3 B Carter, ${ }^{4} \mathrm{~J}$ Snodin. ${ }^{1}$ Evidence-Based Practice Research Centre, Edge Hill University, Ormskirk, UK; ${ }^{2}$ Children's Nursing Research Unit, Alder Hey Children's NHS Foundation Trust, Liverpool, UK; ${ }^{3}$ School of Health, University of Central Lancashire, Preston, UK; ${ }^{4}$ Faculty of Health and Social Care, Edge Hill University, Ormskirk, UK

\subsection{6/archdischild-2015-308599.228}

Aim This presentation will review current evidence on clinical holding and discuss how holding children, for clinical procedures against their wishes, can create tension between children's rights and agency and health professionals' duty to care and to act in the best interests of children in their care.

Method A narrative synthesis approach used systematic procedures to search and appraise the current empirical evidence relating to children being held for procedures within an acute children's care setting. Children in mental health, dental, primary care and anaesthetic settings were excluded from the review.

Findings Empirical evidence demonstrates that children are frequently held for procedures to be completed within acute care settings. The delineation between holding and restraint is poorly defined. Children's protests and distress are reported as taking lower precedence in a decision to hold a child for a procedure than either clinical need or the interests of the adults present. Parents and health professionals expressed feelings of distress, uncertainty, guilt and upset associated with clinical holding. Despite this, alternatives to holding are not always explored and health professionals maintain that the child's best interests are served by a procedure being completed quickly at the expense of short-term distress; the end justifiying the means. This approach neither takes into consideration the possible long-term psychological consequences of holding or restraining children for nonurgent procedures nor how their rights and agency are protected by the adults charged with advocating for them. Evidence suggests that current practice is weighted towards an adult centred approach and that consideration needs to be given to how practice can be tipped towards a child centred approach.

Conclusion Although children are reported as being frequently held for clinical procedures, there is very little quality empirical data or critical ethical debate to inform practice. The lack of robust evidence and clear definitions of what constitutes holding perpetuate this being an almost invisible and taken for granted part of children's care within acute settings.

\section{G236} BRIDGING THE GAP; FROM FAMILY CENTRED CARE TO FAMILY - ENABLED CARE?

P Curtis, A Northcott, J Reid. School of Nursing and Midwifery, University of Sheffield, Sheffield, UK; Sheffield Children's NHS Foundation Trust, Sheffield, UK

\subsection{6/archdischild-2015-308599.229}

Aims The concept of family centred care (FCC) has informed the provision of care to hospitalised children since the late 1980s. However, there is a well acknowledged gap between the principles and practice of FCC. Differences between the expectations of care providers have been demonstrated as has nurses' reticence to share decision-making and cede control to family members. Family members, in turn, have pointed to the lack of support received from nurses. This paper presents findings from a study which sought to explore the potential for care contracts to support family - enabled hospital care for children.

Methods A 10 month, focused ethnographic study was carried out in 2 medical and 2 surgical wards in one Children's Hospital in the North of England. Data, focusing upon activities of daily living and the administration of oral medication, were generated via observation, interviews and focus group discussion with 144 family members (children aged up to 15 and their parent/s) and 65 nurses and Health Care Assistants. All data were subjected to thematic analysis.

Results Although parents generally considered it their 'duty' to provide basic care for their children while in hospital, they did not necessarily know what they were 'allowed' to do or how they might achieve this. This role confusion was particularly significant during acute, short stay hospitalisations. Nurses recognised the vital role that parents' play in care provision and considered it their responsibility to control and direct negotiations with family members. Both parents and nurses valued informal aspects of care negotiation and neither considered formal contracts to be the way forward.

Conclusions There remains clear evidence of a gap between the principles and practice of FCC, particularly during one-off and short stay hospitalisations, which account for a significant proportion of all admissions. This paper will conclude by suggesting approaches that may enable parents' participation in their child's care that could also be, on the basis of our findings, acceptable to nurses.

\section{G237 FAMILY-CENTRED CUBICLES? ISSUES ASSOCIATED WITH DELIVERING AND RECEIVING CARE IN CUBICLES}

${ }^{1}$ A Northcott, ${ }^{1} \mathrm{P}$ Curtis, ${ }^{2} \mathrm{~J}$ Reid. 'School of Nursing and Midwifery, University of Sheffield, Sheffield, UK; ${ }^{2}$ Sheffield Children's NHS Foundation Trust, Sheffield, UK

\subsection{6/archdischild-2015-308599.230}

Aims Spatial aspects of hospitals have received scant attention in research on Family Centred Care (FCC). Presently, cubicles are used predominantly to isolate patients that present an infection risk or that require a heightened level of observation. Though shared bays remain a common feature on children's wards, new builds tend to increase the number of cubicles at the expense of bays. This paper explores the experiences and expectations of nurses and family members as they provided and received care in hospital cubicles.

Methods A 10 month, focused ethnographic study was carried out in 2 medical and 2 surgical wards in a Children's Hospital in the North of England. Data, focusing upon activities of daily living and the administration of oral medication, were generated 